\title{
Mental Functioning of Workers with Cancer Diagnosis by Brazilian Version of the Work Role Functioning Questionnaire-WRFQ-Br
}

\author{
Cristiane Helena Gallasch', Neusa Maria Costa Alexandre², Sergio Carlos Barros Esteves ${ }^{3}$, \\ Eugenio Fuentes Pérez Júnior1, Magda Guimarães de Araujo Faria1, Elias Barbosa de Oliveira4, \\ Priscila Cristina da Silva Thiengo ${ }^{1}$, Patricia Campos Pavan Baptista ${ }^{5}$
}

\footnotetext{
${ }^{1}$ Faculty of Nursing, Rio de Janeiro State University, Rio de Janeiro, Brazil

${ }^{2}$ Post Graduation Programs Professor, Group of Studies and Researches in Occupational Health and Ergonomics Leader, Faculty of Nursing, State University of Campinas, Campinas, Brazil

${ }^{3}$ CAISM Hospital da Mulher Dr. José Aristodemo Pinotti, State University of Campinas, Campinas, Brazil

${ }^{4}$ Post Graduation and Under Graduation Programs Professor, Mental Health and Work, Study Group Leader (GESMT), Faculty of Nursing, Rio de Janeiro State University, Rio de Janeiro, Brazil

${ }^{5}$ Post Graduation and Under graduation Programs Professor, Leader of the Group of Studies on the Health of Nursing Worker (GESTE), School of Nursing, University of São Paulo, São Paulo, Brazil

Email: cristiane_gallasch@yahoo.com.br
}

How to cite this paper: Gallasch, C.H., Alexandre, N.M.C., Esteves, S.C.B., Júnior, E.F.P., de Araujo Faria, M.G., de Oliveira, E.B., da Silva Thiengo, P.C. and Baptista, P.C.P. (2016) Mental Functioning of Workers with Cancer Diagnosis by Brazilian Version of the Work Role Functioning Questionnaire-WRFQ-Br. Health, 8, 1495-1505. http://dx.doi.org/10.4236/health.2016.814148

Received: October 14, 2016

Accepted: November 13, 2016

Published: November 16, 2016

Copyright $\odot 2016$ by authors and Scientific Research Publishing Inc. This work is licensed under the Creative Commons Attribution International License (CC BY 4.0).

http://creativecommons.org/licenses/by/4.0/

(c) (i) Open Access

\begin{abstract}
Aim: To evaluate data related to mental work functioning of workers with cancer diagnosis in radiotherapy in a private service in the city of Campinas, State of São Paulo, Brazil. Method: It consists in a cross-sectional, observational and analytical study with comparison between cancer patients and healthy people, using the Brazilian version of the Work Role Functioning Questionnaire (WRFQ-Br). Descriptive and statistical analysis is performed by the Mann-Whitney test. Results: There was a significant difference between the groups in the evaluation of mental demand; however, the population diagnosed with malignant neoplasm submitted to radiotherapy had unexpected higher scores, reflecting lower mental exigency. Conclusions: The observed context may occur due to extensive support of family, government and interdisciplinary team of health care for individuals diagnosed with cancer. This data provide support for new research studies related to the importance of the work to promote mental health, considering aspects related to social interaction and productivity as the support system members. The importance of disseminating these results and limitation is based in the necessity of investments to improve research and actions to promote the permanence and early return to work for cancer survivors in Brazil and Latin America.
\end{abstract}




\section{Keywords}

Neoplasms, Mental Health, Social Support, Occupational Health Nursing

\section{Introduction}

Cancer and other chronic diseases represent severe public health problem. They cause physical, psychological and social impairments, as well as absenteeism, labor market exit, and a reduced quality of life [1] [2] [3] [4]. According to the World Health Organization, about 27 million new cases of cancer could happen until 2030, with 17 million deaths and 75 million survivors, due to the increase of life expectancy and risk factors exposure. Approximately 50\% of cases occur in developing countries, such as Brazil, where 576,000 notifications of new cases of cancer were expected per year in 2014 and 2015 [5]. Newer Brazilian data are not available until this moment.

After clinical therapeutic cycles, cancer survivors should move forward with their lives, and to address aspects of work in survivorship is relevant in the rehabilitation process, during and post-treatment to prevent challenges related to "live with cancer diagnosis" [6]. In several countries, including Brazil, many cancer patients remain at work during treatment or return to work soon afterward, since the work provides incomes, such as health insurance, as well as it is a way to maintain social relationships, self-identity and self-esteem. Attention to limitations relative to work demands is warranted in all fields of health, particularly in those who desire or need to work [7].

North American and European studies show work limitations related to cancer survivorship since 2000's. Cancer survivors may present work limitations in up to 11 years after diagnosis and starting treatment [8]. Previous studies using the Work Limitations Questionnaire (WLQ) related fatigue depression, anxiety and cognitive loss in patients after cancer therapies [9] [10]. It is noteworthy that patients may present residual symptoms after chemo- and radiotherapy, causing a direct and negative impact in return to work [7] [11].

For a long time, psychological symptoms of cancer patients were neglected. However, it has recently received increased research attention, recognizing its impact on patients' quality of life [12] [13]. To date, there is still a gap of publications related to the evaluation of psychological/mental disorders in general workers with cancer diagnosis, as well as the impact of these conditions in return to work.

In the present study, we use the mental subscale of the Brazilian version of the Work Role Functioning Questionnaire ( WRFQ-Br), by measuring cognitive demands, including attention and concentration. The WRFQ-Br has shown good reliability and validity in populations with musculoskeletal symptoms and among workers with cancer diagnosis in radiotherapy, i.e., it is an appropriate instrument to measure the mental functioning of workers with chronic health conditions [14] [15] [16].

Considering the lack of research and literature in Brazil in this context, the aim of 
this study is to investigate mental functioning in workers with cancer diagnoses when in radiotherapy. It is expected to find lower mental functioning scores for patients when compared to healthy workers.

\section{Methods}

\subsection{Ethical Considerations}

The full research protocol and the informed consent were approved by the Faculty of Medical Sciences, State University of Campinas' Ethics Committee, being identified by CAAE 4840.0.000.146-09 and report number 1104/2009, following the Helsinki Declaration and all Ethics Brazilian regulation law.

\subsection{Study Design}

The present study concerns a cross-sectional, observational study, testing the hypothesis that workers with cancer diagnosis in radiotherapy have significantly different scores for mental work functioning demand than healthy workers.

\subsection{Subjects and Setting}

The study included cancer patients receiving radiotherapy in a private health service in the state of São Paulo, where people with any age and miscellaneous social, economic and educational level can be attended, through private health insurance or paid service. Fifty-one patients who received radio-oncology assistance between 2011 and 2012 and 105 individuals with no complaints were selected to participate.

Inclusion criteria: Symptomatic individuals included in this study comprised literate patients aged 18 - 65 years, with cancer diagnosis confirmed by laboratorial tests, and receiving radiotherapy in a private radiotherapy center, with minimum exposure doses of 2000 cGy or that had radiotherapy recently (for a maximum of 24 months). Workers who maintained formal or informal employment during treatment were included [15], being this the main reason to interview only 51 subjects. In clinical practice, we observed that, even patients don't present complaints; health professionals usually suggest the full removal from work activities during cancer therapies.

Exclusion criteria: Illiterate patients or those with some degree of difficulty in reading and understanding, and/or those who refused to participate, as if those who weren't working during radiotherapy protocol were excluded of this study.

Workers who did not report any health complaints or difficulties at work, who participated of a previous study [14] [15] [16], with similar social, economic and educational were selected among employees at a technological development center in the state of São Paulo, and defined as "Healthy Workers". This inclusion was approved by the ethical committee.

\subsection{Instruments and Data Collection}

Based on previous research, a form containing questions about age, gender, diagnosis, therapeutic protocol, date of the last radiotherapy session, educational level, occupa- 
tion, job hours per week, period of work and complaints about health was performed to define population socio, demographic and clinical data characteristics [14]. Thereafter, occupations were classified as job types according to Hébert's classification [17], following the same methods as previous studies.

The Brazilian version of the WRFQ (WRFQ-Br) was used to examine mental work functioning demand, considering the importance of to evaluate this population feature, as explained above. The WRFQ-br examines the percentage of time that workers have difficulties in accomplishing the work demands due to health problems [18] [19] [20]. This health measurement tool was translated and had its psychometric properties evaluated for whole instrument ad for each subscale to Brazilian workers in previous studies [14] [16].

Patient's data were collected in the radiotherapy center, for those who were still in treatment. For those who had finished treatment, data were collected in home visits, or by sending a postal questionnaire. In a phone call prior to data collection, patients were asked to choose how they would like to complete the questionnaire. Healthy workers answered the questionnaire at the workplace, after having received information about the study objectives.

\subsection{Statistical Analyses}

Initially, a descriptive analysis was carried out to characterize the participants. Data collected were entered into data bank (Microsoft Office Excel 2007, SAS version 9.2 Cary, NC, USA: SAS Institute Inc., 2008 and R-project 2.15.0) and submitted to statistical analysis with the collaboration of the University's Statistics Department.

To compare patients with healthy population, as results did not demonstrate a normal distribution, and only two variables were obtained, the Mann-Whitney test was used to perform data evaluation.

\section{Results}

Socio-demographic characteristics of all subjects are described in Table 1. Occupations were classified as job types according to Hébert's classification [17]. The mean score for mental functioning evaluated using the WRFQ-Br is shown in Table 2 and in Figure 1.

Difference about age between groups was observed as expected, with older people between patients. Both presented majority of workers in mixed activities of work, with no statistical difference about weekly work hours.

Majority of cancer diagnosis were breast cancer (45.1\%) and prostate cancer (23.5\%). Other cancer diagnosis concerned non-Hodgkin's Lymphoma (5.9\%), rectum, uterus, parotid, stomach, pharynx, skin, bones and bladder cancer.

There was a significant difference between cancer patients and healthy workers regard to mental work functioning, which was proposed as hypothesis of this study. Notably, patients with cancer diagnosis in radiotherapy had higher scores for mental work functioning. 
Table 1. Socio-demographic, clinical and laboral characteristics. Campinas, São Paulo, Brazil, 2013.

\begin{tabular}{|c|c|c|c|}
\hline & $\begin{array}{l}\text { Workers in radiotherapy } \\
\qquad(\mathrm{n}=51)\end{array}$ & $\begin{array}{l}\text { Workers with no health } \\
\text { complains }(\mathrm{n}=105)\end{array}$ & p-value \\
\hline \multicolumn{4}{|l|}{ Gendern (\%) } \\
\hline Male & $23(45.1)$ & $46(43.8)$ & \\
\hline Female & $28(54.9)$ & $59(56.2)$ & \\
\hline Mean age (years $( \pm \mathrm{SD})$ ) & $53.4(10.1)$ & $34.8(11.8)$ & $<0.0001$ \\
\hline \multicolumn{4}{|l|}{ Cancer Diagnoses } \\
\hline Breast & $23(45.10)$ & & \\
\hline Prostate & $12(23.53)$ & & \\
\hline Head and Neck & $4(7.85)$ & & \\
\hline Non Hodgkin Limphoma & $3(5.88)$ & & \\
\hline Rectum & $2(3.92)$ & & \\
\hline Uterus & $2(3.92)$ & & \\
\hline Stomach & $2(3.92)$ & & \\
\hline Others & $3(5.88)$ & & \\
\hline \multicolumn{4}{|l|}{ Educational Leveln (\%) } \\
\hline Elementary & $9(17.6)$ & $3(2.9)$ & \\
\hline High school & $6(11.8)$ & $35(33.3)$ & \\
\hline Undergraduation & $28(54.9)$ & $44(41.9)$ & \\
\hline Post-graduation & $8(15.7)$ & $23(21.9)$ & \\
\hline Mean weekly work hours $( \pm S D)$ & $41.5(10.0)$ & $40.6(2.5)$ & 0.0663 \\
\hline Mean Period of job (years $( \pm S D)$ ) & $20.3(11.9)$ & $9.9(10.0)$ & $<0.0001$ \\
\hline \multicolumn{4}{|l|}{ Job Type n (\%) } \\
\hline Manual & $13(25.5)$ & $14(13.3)$ & \\
\hline Mixed & $21(41.2)$ & $65(61.9)$ & \\
\hline Non-Manual & $17(33.3)$ & $26(24.8)$ & \\
\hline
\end{tabular}

${ }^{*}$ Mann-Whitney test.

Table 2. Mean score for mental work functioning. Campinas, São Paulo, Brazil, 2013.

\begin{tabular}{cccccc}
\hline & $\begin{array}{c}\text { Workers in radiotherapy } \\
(\mathrm{n}=51)\end{array}$ & $\begin{array}{c}\text { Workers with no health complains } \\
(\mathrm{n}=105)\end{array}$ & p-value* \\
\hline & $\mu( \pm \mathrm{SD})$ & Median & $\mu( \pm \mathrm{SD})$ & Median & \\
\hline Mental Work Functioning & $89.05(16,57)$ & 95.83 & $86.07(13,72)$ & 87.50 & 0.0189 \\
\hline
\end{tabular}

${ }^{*}$ Mann-Whitney test. 


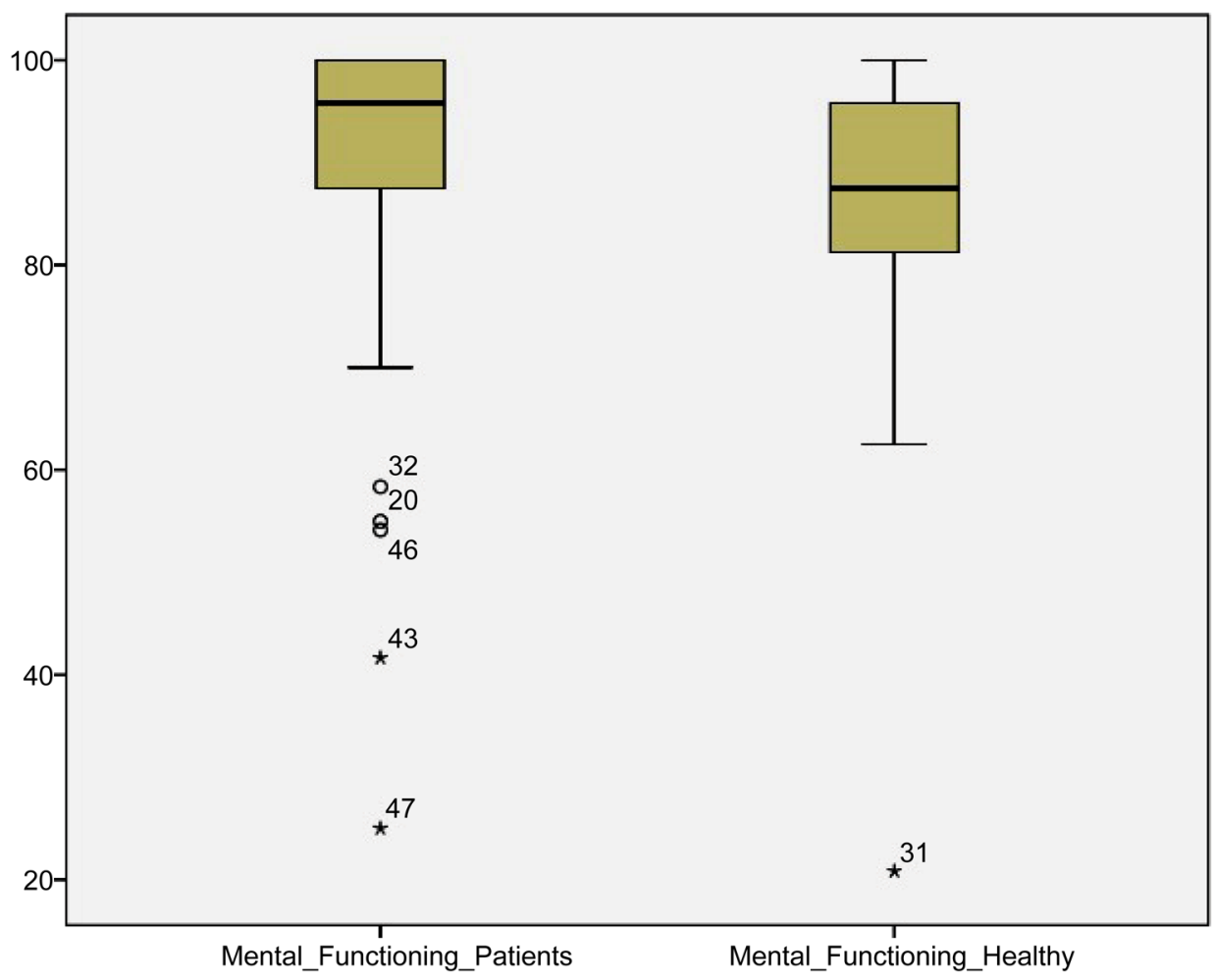

Figure 1. Mean score for mental work functioning compared by box plot. Campinas, São Paulo, Brazil, 2013.

\section{Discussion}

In this study, we found mental work functioning between the observed groups. Unexpectedly, cancer patients presented higher mental work functioning than healthy patients. It may be associated with the patient's function in the family, at work, hence into society [21]. The systematic involvement of health professionals in psychosocial support to the work of cancer patients and the integration among physicians involved in the treatment and occupational characteristics may facilitate the return to work activities [22].

The possible explication is that worker diagnosed with cancer receives largest health multidisciplinary support to return to work, in addition to better understanding and protection from all stakeholders. It is wondered if part of this population may not differ from the general population in some aspects of health evaluation. It is relevant to recollect that all patients kept their work activities, which may represent better clinical conditions in the moment of the study.

Statistical difference age and period of job between groups is expected, since they are common characteristics of cancer diseases, which has as one of its risk factors population aging and increased life expectancy. Furthermore, sample was determined by social, economic and educational level characteristics, but age was not a standard to invitation. Following Brazilian statistics [5] there is majority of prostate cancer for men (23.5\%) and breast cancer for women (45.1\%). 
Work has been understood as part of the world experienced by the subject, his/her body and his social relations, representing a way of enjoyment or pain, resulting in different expressions of productivity and creativity [23]. Through the work human can find his/her place in the community [21]. In a perspective of labor as a source of pleasure, it is necessary to consider the centrality of work in the human life, contributing to the identity formation, influencing self-perception about the world and subjective building of desires and life projects. So, as explained since 1990's by the one of the most important authors who study psychodynamic, work may act positively on worker mental health strengthening psychic reserves when configured as a source of pleasure and satisfaction [24].

Due to high physical and mental requirement in work, there is a great amount of removal from job activities between patients with cancer diagnosis. In Brazil, there is a gap of information about removal, but it is know that in the year of this study, more than 130,000 financial social benefits were given to workers during cancer treatment [25]. In this study, it was observed $13.4 \%$ of patients were out of work, even after the end of treatment. There are no clear data about how to assess ability/disability of these individuals or attempts of work environment adaptation, reducing output/schedule demands or journey, as ways of avoiding total removal of labor activities.

The increased survival rate after cancer treatment for individuals in economically active age expands the chances of staying or returning to work activities. This rate of return to work varies according to the characteristics of the support of each country, including health systems, rehabilitation and social systems [26].

This context is one of the reflections of this study. Considering social role of work and all support systems and stakeholders procedures related to it, with direct influence on psychosocial aspects of health, how the maintenance work activities could do a positive role in the management of stress and coping of that patients? Authors know, because of their clinical practice, that may times it is not possible for patients to maintain full-time work activities due to the necessity to attend to health services appointments, and because of clinical symptoms related to the treatment protocols.

However, would all individuals need the full removal in Brazilian context? Would be benefits in partial stay on the work environment? Partial removal is a reality in some European countries. In addition, there is the reality of care that many patients with self-employment (autonomous), who keep the work activities, as the only form of subsistence.

Scientific literature describing benefits of working to promote mental health are uncommon, with a predominance of paper about psychosocial damage caused by work activities and few reflections on the positive aspects related to family and social circles involved and their relationship with clinical. Contributions of Dejours' studies highlight to impact of labor on mental life, reinforcing the centrality of work in understanding not only the disease but also health and pleasure [27].

It is highlights that for the individual to experience the work benefits, it should be organized so as to be in line with personal needs, allowing space for the worker to exer- 
cise freedom and creativity in the labor process, experiencing the tasks as a means of mental relaxation. The work can be a balancing form, to provide pleasure during the execution, contributing to the worker feel better than even before to have them started [28]. In this context, the work is able to minimize negative thoughts and anxious crises, strengthening social support through the emotional ties links with his peers in the work relationship.

It is important to remember that worker with cancer diagnosis and receiving radiotherapy lives with a high negative charge resulting from disease prognosis and lifestyle changes imposed by the treatment, being subject to the imbalance of his/her mental health. Self-image, identity, wishes and life perspectives are directly affected. Thereby, it is necessary to reflect on the impact of sick leave in the fear of worthlessness, lack of recognition and maintenance of its survival on their subjectivity [29].

In Brazilian context, occupational health, psychology, psychiatry and oncology professionals need to talk with compensation systems and other stakeholders and to access more information to develop interdisciplinary skills that allow promoting changes in the workplace and the improvement of actions to promote permanence and early return to work [6].

Authors understand that the small sample size is a limitation of this study, however, since it was intended to approach individuals who kept their work activities even during radiotherapy, this scene reflects the behavior of Brazilian public and private health systems, with a predominant behavior of removing individuals diagnosed with cancer from work activities. The importance of disseminate these results and limitation is based in the necessity of investments to improve research and actions to promote the permanence and early return to work for cancer survivors in Brazil and Latin America.

\section{Conclusions}

The study has shown that there are significant differences between patients with cancer diagnosis in radiotherapy and healthy population. Results refuted the hypothesis that the lower mental functioning scores would be found in patients when compared to healthy workers.

Authors propose that it may happen due to extensive support of family, government, interdisciplinary team of health care and others stakeholders for individuals diagnosed with cancer provided by a better comprehension of the disease, which is observed during clinical practice in oncology.

The study was conducted to deal with the challenge of expanding discussions about cancer survivors in Brazil. It is necessary to find strategies to identify work functioning and to promote work changes and to reorganize the work process for this population, considering the new reality of survivorship after cancer treatment.

Furthermore, it is necessary to enhance the role of transdisciplinary effort to assist worker return to work, according to his/her individual clinical conditions and the type of activity that will be developed in the workplace.

Also, any activities, depending of the workers profile, including literacy and life ex- 
periences, can be a cause of suffering, and the return to the old function is not the better choice.

It is hoped that the data can provide support for new research studies related to the importance of the work to promote mental health, considering aspects related to social interaction and productivity as the support system members

\section{Acknowledgements}

Authors thank to Coordination for the Improvement of Higher Education Personnel (CAPES) for supporting this study.

\section{References}

[1] Feuerstein, M. (2005) Introduction: The World Challenge of Work Disability. Journal of Occupational Rehabilitation, 15, 451-452. http://dx.doi.org/10.1007/s10926-005-8026-Z

[2] Steiner, J.F., Nowels, C.T. and Main, D.S. (2010) Returning to Work after Cancer: Quantitative Studies and Prototypical Narratives. Psychooncology, 19, 115-124.

http://dx.doi.org/10.1002/pon.1591

[3] DiBonaventura, M.C., Gupta, S., McDonald, M., et al. (2012) Impact of Self-Rated Osteoarthritis Severity in an Employed Population: Cross-Sectional Analysis of Data from the National Health and Wellness Survey. Health and Quality of Life Outcomes, 10, 30. http://dx.doi.org/10.1186/1477-7525-10-30

[4] Dall, T.M., Gallo, P., Koenig, L., et al. (2013) Modeling the Indirect Economic Implications of Musculoskeletal Disorders and Treatment. Cost Effectiveness Resource Allocation, 11, 5. http://dx.doi.org/10.1186/1478-7547-11-5

[5] Brasil (2007) Ministério da Saúde. Secretaria de Atenção à Saúde. Instituto Nacional de Câncer. Coordenação de Prevenção e Vigilância de Câncer. Estimativas 2008: Incidência de Câncer no Brasil. INC, Rio de Janeiro.

[6] Feuerstein, M. (2007) Defining Cancer Survivorship. Journal of Cancer Survivorship, 1, 5-7. http://dx.doi.org/10.1007/978-0-387-34562-8

[7] Moskowitz, M.C., Todd, B.L., Chen, R., et al. (2014) Function and Friction at Work: A Multidimensional Analysis of Work Outcomes in Cancer Survivors. Journal of Cancer Survivorship, 8, 173-182. http://dx.doi.org/10.1007/s11764-013-0340-4

[8] Yabroff, R., Lawrence, W.F., Clauser, S., et al. (2004) Burden of Illness in Cancer Survivors: Findings from a Population-Based National Sample. Journal of National Cancer Institute, 96, 1322-1330. http://dx.doi.org/10.1093/jnci/djh255

[9] Feuerstein, M., Hansen, J.A., Calvio, L.C., et al. (2007) Work Productivity in Brain Tumor Survivors. Journal of Occupational and Environmental Medicine, 49, 803-811. http://dx.doi.org/10.1097/JOM.0b013e318095a458

[10] Hansen, J.A., Feuerstein, M., Calvio, L.C., et al. (2008) Breast Cancer Survivors at Work. Journal of Occupational and Environmental Medicine, 50, 777-784. http://dx.doi.org/10.1097/JOM.0b013e318165159e

[11] Tevaarwerk, A.J., Lee, J.W., Sesto, M.E., et al. (2013) Employment Outcomes among Survivors of Common Cancers: The Symptom Outcomes and Practice Patterns (SOAPP) Study. Journal of Cancer Survivorship, 7, 191-202. http://dx.doi.org/10.1007/s11764-012-0258-2

[12] Zabora, J. (2001) The Prevalence of Psychological Distress by Cancer Site. Psychooncology, $10,19-28$. 
http://dx.doi.org/10.1002/1099-1611(200101/02)10:1<19::AID-PON501>3.0.CO;2-6

[13] Artherholt, S.B. and Fann, J.R. (2012) Psychosocial Care in Cancer. Current Psychiatry Reports, 14, 23-29. http://dx.doi.org/10.1007/s11920-011-0246-7

[14] Gallasch, C.H., Alexandre, N.M.C. and Amick, B.C. (2007) Cross-Cultural Adaptation, Reliability and Validity of the Work Role Functioning Questionnaire to Brazilian Portuguese. Journal of Occupational Rehabilitation, 17, 701-711. http://dx.doi.org/10.1007/s10926-007-9103-2

[15] Abma, F.I., Van der Klink, J.J. and Bültmann, U. (2013) The Work Role Functioning Questionnaire 2.0 (Dutch Version): Examination of Its Reliability, Validity and Responsiveness in the General Working Population. Journal of Occupational Rehabilitation, 23,135-147. http://dx.doi.org/10.1007/s10926-012-9379-8

[16] Gallasch, C.H., Alexandre, N.M.C. and Esteves, S.C.B. (2015) Psychometric Properties of the Brazilian Version of the Work Role Functioning Questionnaire Evaluating Workers in Radiotherapy. UERJ Nursing Journal, 23, 817-824.

http://dx.doi.org/10.12957/reuerj.2015.15791

[17] Hébert, F. (1996) Les indicateurs de lésions em santé et sécurité au travaiul: analyses par secteur d'activitééconomique em 1991. Institut de recherche Robert-Sauvé em santé et sécurité au travail, Montreaul.

[18] Lerner, D., Amick, B.C., Lee, J.C., et al. (2003) Relationship of Employee-Reported Work Limitations to Work Productivity. Medical Care, 41, 649-659.

http://dx.doi.org/10.1097/01.MLR.0000062551.76504.A9

[19] Amick, B.C., Habeck, R.V., Ossmann, J., et al. (2004) Predictors of Successful Work Role Functioning Alter Carpal Tunnel Release Surgery. Journal of Occupational and Environmental Medicine, 46, 490-500.

http://dx.doi.org/10.1097/01.jom.0000126029.07223.a0

[20] Durand, M.J., Vachon, B., Hong, Q.N., et al. (2004) The Cross-Cultural Adaptation of the Work Role Functioning Questionnaire in Canadian French. International Journal of Rehabilitation Research, 27, 261-268. http://dx.doi.org/10.1097/00004356-200412000-00002

[21] Inada, J.F. (2011) Happiness and Discontents in the Civilization. Revista Digital Adverbum, 6, 74-88.

http://www.psicanaliseefilosofia.com.br/adverbum/vol6_1/06_01_06felicidademalestarcivili z.pdf

[22] Tamminga, S.J., de Boer, A.G., Bos, M.M., et al. (2012) A Hospital-Based Work Support Intervention to Enhance the Return to Work of Cancer Patients: A Process Evaluation. Journal of Occupational Rehabilitation, 22, 565-578. http://dx.doi.org/10.1007/s10926-012-9372-2

[23] Mendes, A.M.B. (1995) Aspectos psicodinâmicos da relação homem-trabalho: as contribuições de C. Dejours. Psicologia: Ciência e Profissão, 15, 34-38.

http://www.scielo.br/scielo.php?script=sci_arttext\&pid=S1414-98931995000100009 http://dx.doi.org/10.1590/s1414-98931995000100009

[24] Dejours, C. (1992) Loucura do trabalho. Oboré, São Paulo.

[25] Brasil (2015) Ministério da Previdência Social. Instituto Nacional do Seguro Social. Empresa de tecnologia e informações da Previdência Social. Anuário Estatístico da Previdência Social 2013, Brasília, Brazil.

http://www.mtps.gov.br/dados-abertos/dados-da-previdencia/previdencia-social-e-inss/anu ario-estatistico-da-previdencia-social-aeps

[26] Rick, O., Kalusche, E.M., Dauelsberg, T., et al. (2012) Reintegrating Cancer Patients into the 
Workplace. Deutsches Ärzteblatt International, 109, 102-108.

[27] Bouyer, G.C. (2010) Contribution of Psychodinamics of Work to the Debate "The Contemporary World of Work and Worker's Mental Health". Revista Brasileira de Saúde Ocupacional, 35, 249-259. http://www.scielo.br/pdf/rbso/v35n122/a07v35n122.pdf

[28] Dejours, C., Abdoucheli, E. and Jayet, C. (2010) Psicodinâmica do Trabalho Contribuições da Escola Dejouriana à análise da relação prazer, sofrimento e trabalho. Atlas, São Paulo.

[29] Dejours, C. (2011) A banalização da injustiça social. Editora da FGV, Rio de Janeiro.

Submit or recommend next manuscript to SCIRP and we will provide best service for you:

Accepting pre-submission inquiries through Email, Facebook, LinkedIn, Twitter, etc. A wide selection of journals (inclusive of 9 subjects, more than 200 journals)

Providing 24-hour high-quality service

User-friendly online submission system

Fair and swift peer-review system

Efficient typesetting and proofreading procedure

Display of the result of downloads and visits, as well as the number of cited articles

Maximum dissemination of your research work

Submit your manuscript at: http://papersubmission.scirp.org/

Or contact health@scirp.org 